\title{
Seismic-Geodynamic Monitoring of Main Electric Power-Stations in East Europe and North Asia
}

\author{
Yury Gatinsky $^{1}$, Dmitry Rundquist ${ }^{1}$, Galina Vladova ${ }^{2}$, Tatiana Prokhorova ${ }^{2}$ \\ ${ }^{1}$ Vernadsky State Geological Museum RAS, Moscow, Russia \\ ${ }^{2}$ International Institute of Earthquake Prediction and Mathematical Geophysics RAS, Moscow, Russia \\ E-mail: yug@sgm.ru \\ Received February 22, 2011; revised April 6, 2011; accepted May 6, 2011
}

\begin{abstract}
In east Europe and north Asia the majority of nuclear power-stations (NPS) as well as large hydro-electric (HES) and thermal electric stations (TES) are located within the north Eurasian lithosphere plate, which is characterized by the low seismicity and weak modern tectonic activity besides the different exogenetic processes. Some operating and projected NPS are relatively near to zones of the moderate seismicity in the Kaliningrad Region of northwest Russia and in south Ukraine. HES and TES in Baltic, Byelorussia and Ukraine are in the same position. Zones of more intensive seismicity and existence of active faults include NPS, HEP and TEP in the Urals, the Kola Peninsula, south Siberia, Transbaikal and Far East regions of Russia. Some of these stations are situated within crust blocks in transit zones, which separate main lithosphere plates and are characterized by increased tectonic mobility. The electric power-stations are most danger in the transit zones between north Eurasian, Arabian and Indian lithosphere plates, where collision processes have yet not stopped. This concerns electric stations in central Asia and Caucasus including NPS in Armenia. Seven schemes of the seismic energy distribution are composed for different parts of east Europe and north Asia. The location of nuclear and main other electric power-stations on them makes it possible to form a correct estimate of negative consequences connected with the up-to-date inner-continental tectonic activity.
\end{abstract}

Keywords: Electric Power-Station, Seismicity, Active Fault, Lithosphere Plate, Transit Zone, Crust Block, Seismic Energy

\section{Introduction}

The paper is devoted to results of investigation of the seismicity and active faults distribution in regions of operating, projected and closed NPS after data of the International Nuclear Safety Center (http://www.insc.anl. gov/pwrmaps) as well as large HES and TES after the List of largest power stations in the world (http://en.wikipedia.org/wiki/List_of_largest_power_stations_in_the world) in the territory of east Europe and north Asia. Our aim is to estimate the level of risk in the stations' functioning under the influence of the up-to-date tectonic activity. The fulfilling of this investigation is connected with the solution of the fundamental scientific problem concerning the nature of the increased inner-continental seismicity and a pattern of its propagating within north Eurasia. The methods of investigation consisted in the detailed analysis of geological data and in some regions also space images of different scales. Data on displacements along active faults [1] together with space-geodetic measurements (http://itrf.ensg.ign.fr/) permitted to evaluate in a first approximation the horizontal and vertical mobility of crust blocks within investigated regions. Seven small-scale schemes were constructed for these regions with showing power-stations placing, active faults and the distribution of the seismic energy in region areas after catalogues of NEIC (http://earthquake.usgs. gov/regional/neic/) and CMT (http://www.seismology. harvard.edu/). Velocities and gradients of modern crust displacements were established by these means as well as changes of the seismic energy volume. The schemes contain also boundaries of lithosphere plates, separating them transit zones and crust blocks according to results of previous authors' investigations.

As it was established earlier [2] most parts of east Europe and north Asia belongs to a large north Eurasian 
lithosphere plate, which boundaries are: the Gakkel Ridge and seismoactive faults in the Chersky Range, zones of active faults in south Verchoyanie, Stanovoi Range, the Baikal Rift, Altai - Sayany Region and Tien Shan, the Pamirs Syntax, fault zones of the Kopetdag, Caucasus, the region west of the Black Sea, the Carpathians and Alps. A blocks framework of the plate was characterized in detail in some papers [3-5], in which transit zones were distinguished on its boundaries with neighboring lithosphere plates. The zones contain a number of crustal blocks and represent areas of the transfer and relaxation of the tectonic energy arising in the result of main plates' interaction. It is the principal picture of up-to-date tectonic of east Europe and north Asia, peculiarities of which will be showed below.

\section{West and Central Parts of East Europe}

Power-stations in the west of the European part of Russia, Ukraine, Byelorussia and Baltic countries are situated within the north Eurasian Plate with rather low seismicity (Figure 1). A level of the seismic energy releasing here is as a rule not higher than $1 \times 10^{-6} \mathrm{~J}-1 \times 10^{-5} \mathrm{~J}$.

The energy value increases in this region up to $1 \times 10^{8} \mathrm{~J}$ only in border part of the plate in south Poland. Insignificant increasing takes place in the north shore of the Gulf of Finland $\left(1 \times 10^{-4} \mathrm{~J}-1 \times 10^{-2} \mathrm{~J}\right)$, but the nuclear stations in south Finland and west of Sankt-Petersburg in Russia find themselves in $1 \times 10^{-5} \mathrm{~J}$ fields. Areas of other electric stations are practically aseismic. It refers to Novovoronezh and closed Voronezh, operating Smolensk, Kursk and Kalinin NPS in Russia, areas of the Chernobyl Sarcophagus in Ukraine and closed Ignalina Station in east Lithuania as well as to the majority of HES and TES in these areas. Some authors of this paper (Yu. Gatinsky and G. Vladova) took part in the choice of an erection site for the projected Kaliningrad NPS in northwest Russia [6] and proposed for it an area at the left-bank of the Nyamunas on the distance more than $130 \mathrm{~km}$ from the nearest earthquake epicenter on the Baltic Shelf. The proposition was accepted and now NPS is constructed there.

The intensity and vectors of modern crust displacements can be determined by earthquake focal mechanisms and data of space-geodetic measurements. According to CMT catalogue right-lateral slips predominate on the Baltic Shelf near Kaliningrad and left-lateral ones within the Pannonian Block. Most of earthquakes' hypocenters lie on levels from 4 - $10 \mathrm{~km}$ to 30 - $40 \mathrm{~km}$ depth with maximal M 4 - 6. The latter takes place only in zones of active faults of the Pannonian Block in south Poland and in the neighboring territory of the east Carpathians in Slovakia and Rumania. Northeast vectors of the horizontal movement in the ITRF system characterize this part of the north Eurasian Plate. Their azimuth changes from 45 - 49NE in Poland to 51 - 53NE near Kiev and Moscow with the velocity $22-26 \mathrm{~mm} / \mathrm{y}$. The vertical upwarping diminishes from $6-8 \mathrm{~mm} / \mathrm{y}$ within the Baltic Shield in Finland and 4.0 - $4.6 \mathrm{~mm} / \mathrm{y}$ in the Carpathians in south Poland and west Ukraine down to $1.3 \mathrm{~mm} / \mathrm{y}$ in the east part of the region near Moscow. In south direction the crust subsidence begin to predominate ( $1 \mathrm{~mm} / \mathrm{y}$ near Kharkov in Ukraine). GPS data show also the vertical subsidence with the velocity $1.6 \mathrm{~mm} / \mathrm{y}$ in north Poland near the Russia frontier at $30-40 \mathrm{~km}$ southeast from Kaliningrad. South in the neighboring GPS point an upwarping takes place with velocity $1.8 \mathrm{~mm} / \mathrm{y}$ and more south again subsidence exists (1.2 mm/y). Such data indicate a possibility of small amplitude vertical fluctuations of the Earth crust in this territory and confirm our choice of the projecting NPS site in the extreme east part of the Kaliningrad Region.

Thus, the fulfilled monitoring shows the sufficient reliability of operating, projected an closed NPS in the west of the European part of Russia, Ukraine, Byelorussia and Baltic countries in regards to possible nature disasters connected with the high seismicity and displacement along active faults. The same can be said about the majority HES and TES in this region.

\section{Northeast Europe and the Urals}

This region completely belongs to the north Eurasian Plate (Figure 2) including as operating and projecting NPS within the Russia territory in the Urals (Beloyar and South Ural stations) and on the Volga (Balakov Station) as unfinished and closed NPS (Kostroma, Gorki, Tatary and Bashkir stations). All of them are situated in aseismic or low seismic areas as well as large HES on the Volga and Kama and numerous TES. Insignificant increasing of seismic energy volume up to $1 \times 10^{-3} \mathrm{~J}-1 \times$ $10^{-1} \mathrm{~J}$ takes place in the north Urals north-east from Perm, in the upper north Dvina, in the mouth of the Pechora and in the basin of the Urals River at the frontier with Kazakhstan (see Figure 2). The magnitude can reach 5.3 - 5.9 in epicenters of these areas, but large energetic objects are absent there. Some exogenetic earthquakes with magnitudes up to 3.7 took place near the Middle Volga, where they were connected with the collapse sinkhole during karstic processes.

Earthquake energy increases more intensive up to $1 \times$ $10^{1} \mathrm{~J}$ in active faults' zones within the Kola Peninsula south of Murmansk near Kola NPS. Magnitudes reach there after NEIC data 4.0 - 5.1. Slips predominate among active faults in the Kola Peninsula and Urals, but their amplitudes are not more than first millimeters. Accord- 


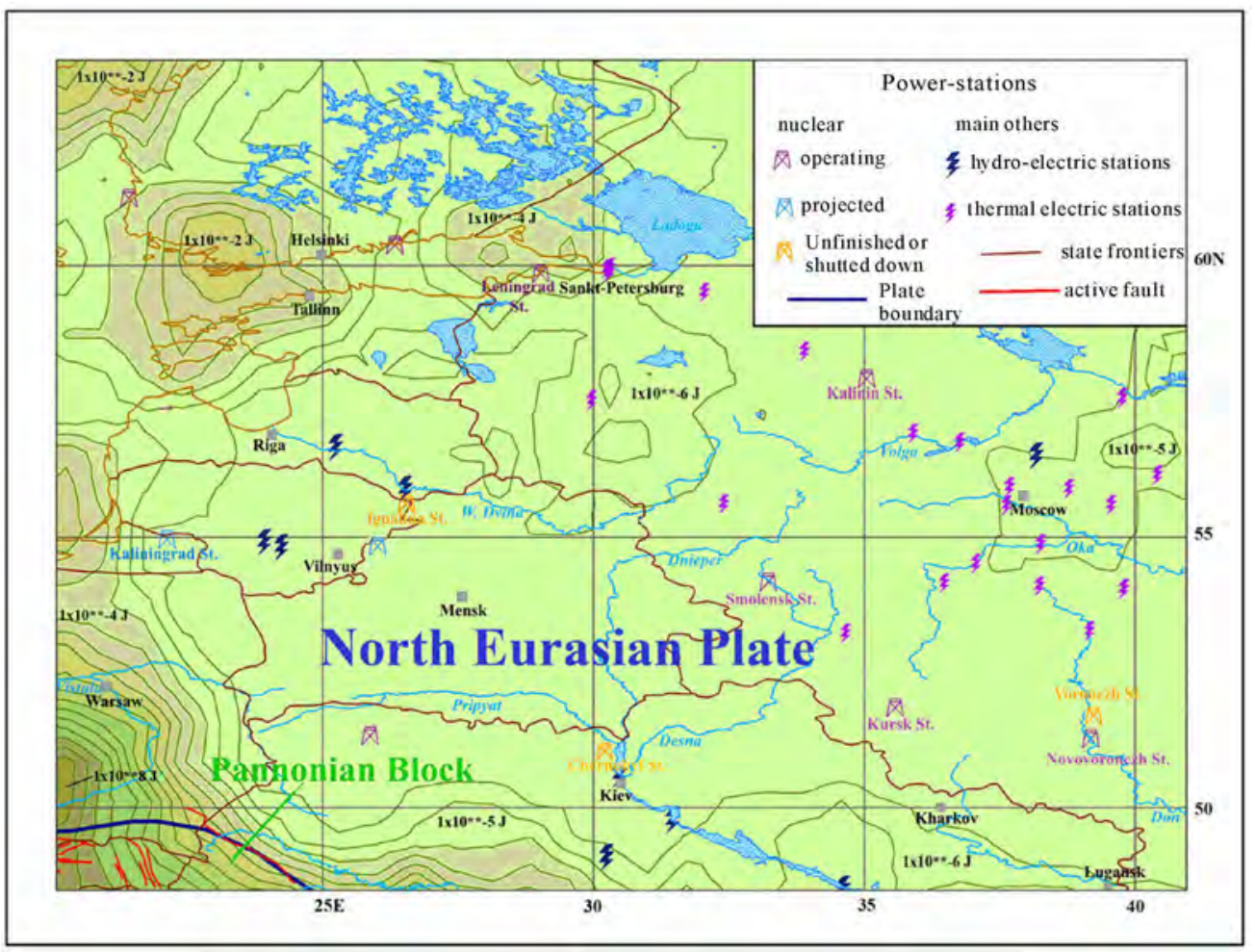

Figure 1. Main power-stations and the seismic energy distribution in the west and central parts of east Europe. Each increasing of the color intensity corresponds to increasing seismic energy volume on $1 \times 10^{-1} \mathrm{~J}$ or $1 \times 10^{1} \mathrm{~J}$. Some energy values are shown in the scheme.

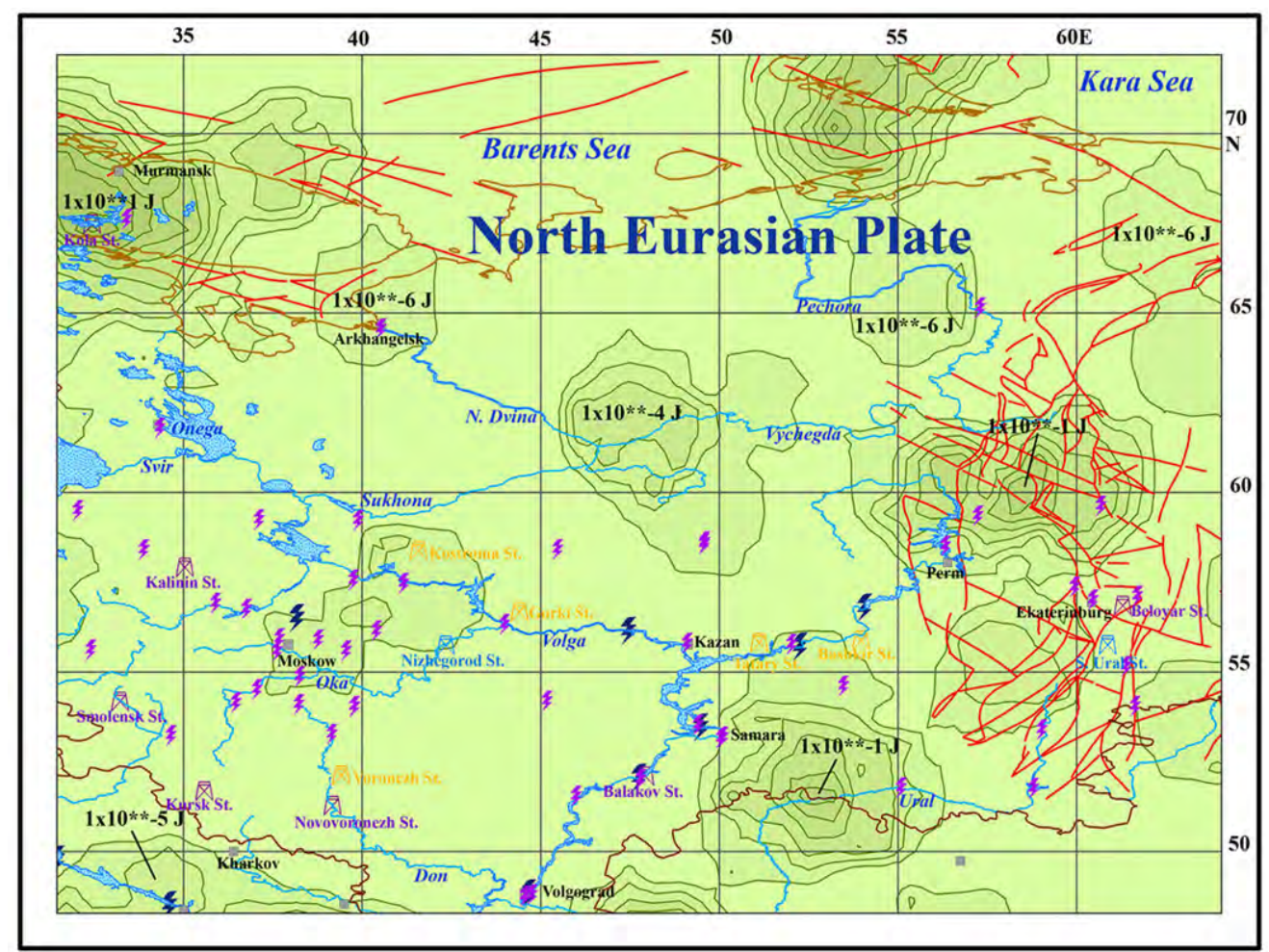

Figure 2. Main power-stations and the seismic energy distribution in northeast Europe and the Urals. For captions see Figure 1. 
ing to GPS data the horizontal displacement continuous in this part of the north Eurasian Plate with velocities 25 $26 \mathrm{~mm} / \mathrm{y}$. Its azimuth changes gradually from 53 - $57 \mathrm{NE}$ in the west up to $70-72 \mathrm{NE}$ in the Urals indicating the weak clock-wise rotation of the plate.

Therefore, we can note that the main part of the energetic objects in investigated region takes place in areas of rather low manifestation of the seismicity and modern tectonic mobility, so they have the sufficient reliability in regards to these processes. Only Kola NPS and some TES in the same territory and in the south Urals are situated in areas, where earthquakes with magnitudes 5.0 5.5 can be. The unfinished and closed stations of this region don't evoke any misgivings in regards to the up-to-date tectonic processes.

\section{Southeast Europe, the Caucasus and Transcaucasus}

This region besides of the most north part of it is characterized by rather high and unevenly distributed seismicity. Its level gradually increases south within the south part of the north Eurasian Plate from $1 \times 10^{-6} \mathrm{~J}-1 \times 10^{-4} \mathrm{~J}$ near Dnieper HES and NPS and Rostov NPS up to $1 \times$ $10^{-2} \mathrm{~J}-1 \times 10^{1} \mathrm{~J}$ in the Steppe Crimea and near Astrakhan at the mouth of the Volga and up to $1 \times 10^{2} \mathrm{~J}$ near the unfinished Odessa NPS in south Ukraine (Figure 3). In the latter place an earthquake with the magnitude 5.0 5.9 occurred some years ago indicating the relative instability of this area. The seismicity level is higher in the south coast of the Crimea near the unfinished Crimea NPS and near Stavropol in front of the north Caucasus (1 $\left.\times 10^{4} \mathrm{~J}-1 \times 10^{6} \mathrm{~J}\right)$. Some TES in Stavropol and Krasnodar Territories of Russia are situated in areas with releasing $1 \times 10^{3} \mathrm{~J}-1 \times 10^{9} \mathrm{~J}$ of the seismic energy.

The maximal modern tectonic activity takes place in the Great Caucasus and Transcaucasus within the Alpine-Iranian transit zone between the north Eurasian and Arabian lithosphere plates (see Figure 3). Some crust blocks are established there, boundaries of which are characterized by very high seismicity [3]. The volume of seismic energy reaches $1 \times 10^{8} \mathrm{~J}-1 \times 10^{13} \mathrm{~J}$ in north front parts of west Caucasus and east Caucasus blocks. Thrusts to the north predominate there with magnitudes in epicenters 4 - 7. Mainly compression takes place also in epicenters along the boundary between east and Lesser Caucasus blocks, but the thrusts are directed there south. Focal mechanisms show a steady right-lateral slip along the north Anatolian Fault on the north boundary of the Anatolian Block with M 4-7 while the transverse northeast fault between the east Pont and Lesser Caucasus blocks is a left-lateral slip [1]. Some northwest rightlateral slips with elements of the compression characterize the inner structure of the Lesser Caucasus including the Yerevan NPS area, where the energy volume amounts to $1 \times 10^{13} \mathrm{~J}$. Right-lateral slips predominate also along the northwest part of the Zagros Fault on the north boundary of the Arabian Plate. Zones with high seismic energy $\left(1 \times 10^{11} \mathrm{~J}-1 \times 10^{13} \mathrm{~J}\right)$ contain HES in north Daghestan, west Georgia and east Armenia.

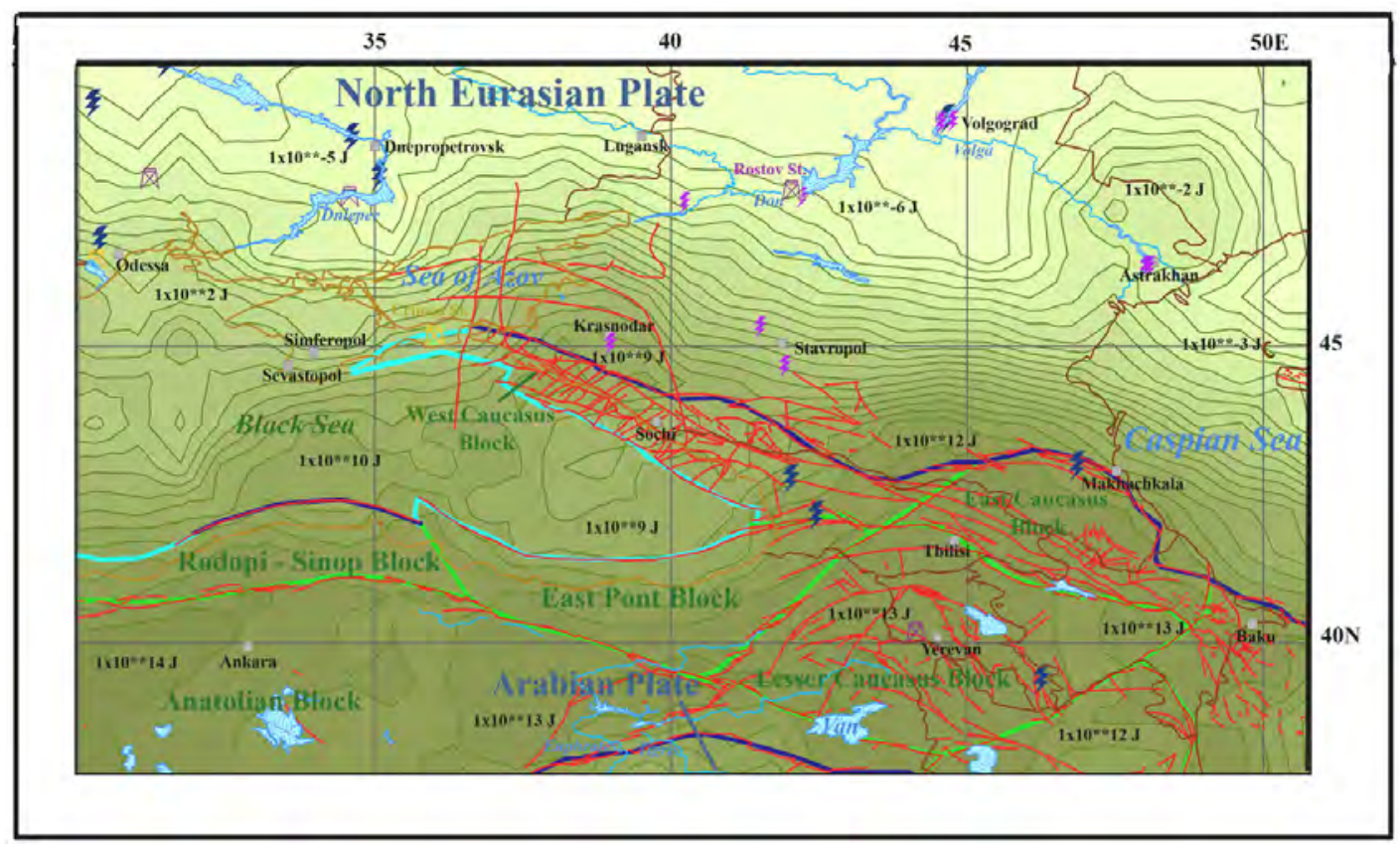

Figure 3. Main power-stations and the seismic energy distribution in southeast Europe, the Caucasus and Transcaucasus. Green lines - block boundaries, light blue lines - supposed boundaries. For other captions see Figure 1. 
Crust blocks of the investigated region move northeast according to ITRF2005 data with velocities 26.8 - $33.6 \mathrm{~mm} / \mathrm{y}$ (the maximal value in Armenia) and the azimuth 50 - 60 NE. In addition a vertical subsidence exists in the south Crimea with the velocity $2.5 \mathrm{~mm} / \mathrm{y}$ and an upwarping with the velocity $1.3 \mathrm{~mm} / \mathrm{y}$ in Yerevan.

As the fulfilled monitoring shows the region of the southeast Europe, the Caucasus and Transcaucasus is one of the most seismic intensive within east Europe and adjacent southwest Asia. The thorough checking of the seismic activity level is needed as for operating as for projecting energetic objects in this region as well as the observance of protective actions during their construction. The following stations are exposed to danger: NPS near Yerevan, unfinished Crimea NPS, some HES in Georgia, Armenia and south Russia in Daghestan, in lesser extent NPS and HES in south Ukraine near Odessa.

\section{Central Asia}

The central Asia region includes the most part of Kazakhstan, Turkmenistan, Uzbekistan, Tadzhikistan and Kirghizia territories as well as adjacent parts of Iran, Afghanistan, Pakistan and China. This region as a previous one is situated in its south half in a zone of increased level of the seismic energy releasing (Figure 4). NPS are absent yet there (the nearest Busher Station operates from 2010 in south Iran), but there are some large HES. Countries of the region possess significant stockpiles of minerals, mining of which now and in future require stepping up the energetic capacity.

The intensity of releasing energy quickly increases to south in the region from $1 \times 10^{-6} \mathrm{~J}-1 \times 10^{-5} \mathrm{~J}$ up to $1 \times$ $10^{12} \mathrm{~J}-1 \times 10^{14} \mathrm{~J}$. High seismic zones with M $7.0-7.9$ and more coincide with active faults in the boundaries between the north Eurasian Plate and Iran, Afghan, Pamir, Tien Shan blocks as well as in the boundaries between some blocks inside the central Asian transit zone [5]. HES near Alma-Ata, Tashkent and Dushanbe lie in these zones. Local energy increasing takes place along some northwest faults, which are transverse in respect of mentioned boundaries. Such increasing (up to $1 \times 10^{3} \mathrm{~J}$ $1 \times 10^{9} \mathrm{~J}$ ) can be shown along the Amu-Darya Fault in southwest Uzbekistan and a fault zone along the Irtish River in east Kazakhstan near Ust Kamenogorsk, where two HES are situated (see Figure 4).

The majority of active faults on block boundaries are thrusts with the south vergence on the north boundary of the Tarim Block and the north vergence in Pamir. Rightlateral slips may be observed more seldom, as example the above mentioned Amu-Darya Fault and the Kopetdag Fault near Ashkhabad. Normal faults are distributed only at sides of intermountain troughs. After GPS data the south part of the north Eurasian Plate moves east-northeast with the azimuth 75 - $83 \mathrm{NE}$, while the majority blocks south of it displace with azimuth 50 - 60 NE. The difference in horizontal moving direction results in the thrusts predominance in the south boundary of

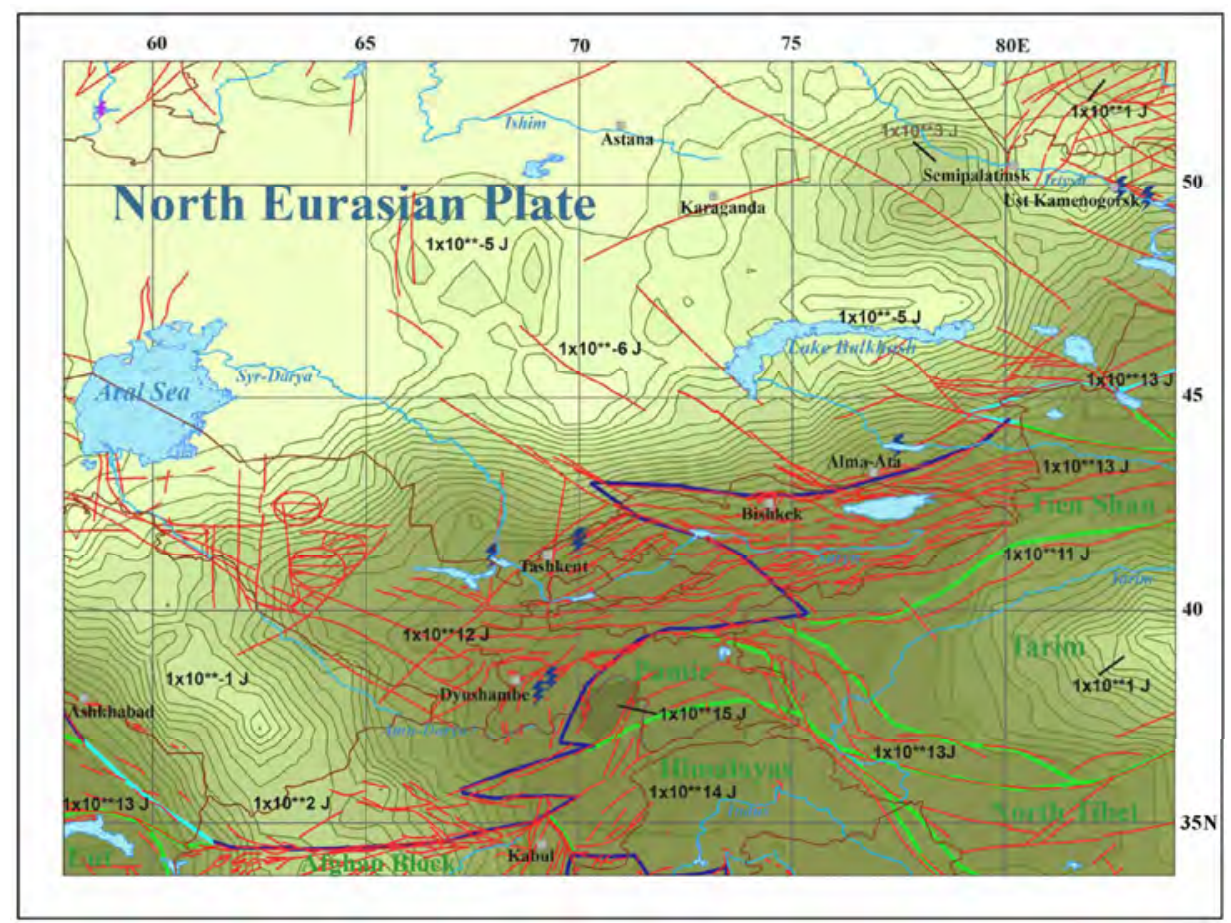

Figure 4. Main power-stations and the seismic energy distribution in central Asia. For captions see Figures 1 and 3. 
the plate [5]. Velocities of horizontal displacements change from $26 \mathrm{~mm} / \mathrm{y}$ to $30 \mathrm{~mm} / \mathrm{y}$ and a vertical upwarping in main mountain ranges occurs with velocities $0.5-2.0 \mathrm{~mm} / \mathrm{y}$.

And so, the central Asian Region is characterized by sharply increased releasing of seismic energy in southwest Turkmenistan and southeast Uzbekistan as well as in Tadzhikistan, Kirghizia and adjacent parts of Afghanistan and China. This requires special measures of the safety as for operating as for projecting electric powerstations in these areas, a control of motions in zones of seismogenic active faults and permanent monitoring of the seismicity level.

\section{South Siberia and Adjacent Parts of China and Mongolia}

NPS are also absent in this region, while large HES and TES are numerous. The south boundaries of the north Eurasian Plate pass through all territory of the region and are expressed by some active faults and fields with increased level of the seismic energy (up to $1 \times 10^{5} \mathrm{~J}-1 \times$ $10^{10} \mathrm{~J}$ ). Maximal its values coincide with the Altai in Russia and west Mongolia as well as with Sayan Mountains in Tyva and north Mongolia (Figure 5). The majority of HES and TES in the region lies in fields with the moderate energy level $\left(1 \times 10^{-5} \mathrm{~J}-1 \times 10^{1} \mathrm{~J}\right)$ and only in the west for stations near Novokuznetsk the level increases up to $1 \times 10^{4} \mathrm{~J}-1 \times 10^{7} \mathrm{~J}$.

Nodes of increased seismicity coincide in this region with intersections of active faults of the different strike: near latitudinal and east-northeast (mainly thrusts) and northwest (in many cases right-lateral slips). Such nodes are widespread in Russia on the boundary of Altai and Sayany blocks with magnitudes in epicenters up to 4.0 7.9, inside the Sayany Block in northwest Mongolia and in other areas. The most intensive earthquakes with $M \geq$ 8 took place in the zone of the active near latitudinal fault between Sayany and Hangay blocks. Note that large energetic objects are absent in mentioned high seismic areas. The most stable blocks possessing the Precambrian basement (Hangay, Junggar) are characterized by noticeable diminishing of the seismicity level in their central parts (see Figure 5).

Thrusts to the south and southwest are noted in the south of the Sayany Block and within the Hangay Block, but to the northeast on the boundary between the Sayany Block and north Eurasian Plate. Practically all northwest faults have a right-lateral component while near latitudinal faults are mainly left-lateral. Normal faults predominate in the southeast part of the Baikal Rift on the boundary of the Amurian Block and north Eurasian Plate, but west from Baikal they change on slips. Vectors of horizontal displacement in the ITRF System change from 75 - 87NE in the west near Novosibirsk in Russia and in northwest China to 96 - 108SE in the east at the Irkutsk and Ulaan-Baatar stations with velocities $20-26 \mathrm{~mm} / \mathrm{y}$. Velocities of the vertical upwarping are not higher than $1.0-1.5 \mathrm{~mm} / \mathrm{y}$.

As was shown above in the investigated region the highest seismicity and tectonic mobility characterize the extreme south part of the north Eurasian Plate and the majority of crust blocks south of it. As a result operating and projecting in future energetic objects have there the increased level of the risk in regards to this activity. The level of the risk is much lower for the objects situated north and west from mentioned areas.

\section{Central Part of the Russian Far East}

Some boundaries of the north Eurasian Plate pass through the region: with the north American Plate along the Chersky Range, Amurian and Japanese-Korean blocks of the east Asian transit zone and the Block of Okhotsk belonging to the north Pacific transit zone [3]. The most active areas coincide just with these boundaries as well as with block boundaries inside transit zones, where the level of seismicity reaches $1 \times 10^{7} \mathrm{~J}-1 \times 10^{14} \mathrm{~J}$ (Figure 6).

Repeated earthquakes took part in these areas with $\mathrm{M}$ up to 7.0 - 7.9, in that number in the Sakhalin Island along the boundary of the Japanese-Korean Block and in the east part of the Sea of Okhotsk within the Block of Okhotsk, in the south of the Khabarovsk Territory and in adjacent parts of China within Japanese-Korean and Amurian blocks. But the majority electric power-stations lie in this region in fields of the energy volume $\leq 1 \times$ $10^{-1} \mathrm{~J}$, including the large HES on the Zeya River. The compression with slip components predominate on the majority plate and block boundaries and mainly the slip regime with compression components in the Sakhalin fault zone [7]. The hypocenter depth doesn't exceed 40 $80 \mathrm{~km}$ and only in the south-east increases up to 480 $640 \mathrm{~km}$ within the Kuril-Kamchatka seismofocal plane connected with the subduction of the Pacific Plate under Eurasia. After results of cosmic-geodetic measurements in the ITRF System the north Eurasian Plate moves on the azimuth 121SE with velocities 22 - $26 \mathrm{~mm} / \mathrm{y}$ (data of Yakutsk and Khabarovsk GPS stations). Vertical displacements change from $+2.4 \mathrm{~mm} / \mathrm{y}$ in Yakutsk to -3 $4 \mathrm{~mm} / \mathrm{I}$ in the tectonic depression near Khabarovsk. The Block of Okhotsk displaces on 149SE after measurements in the Magadan GPS Station. As a result of that the compression exists on its boundary with the north Eurasian Plate west of Magadan.

Thus we can note that in the investigated region zones 


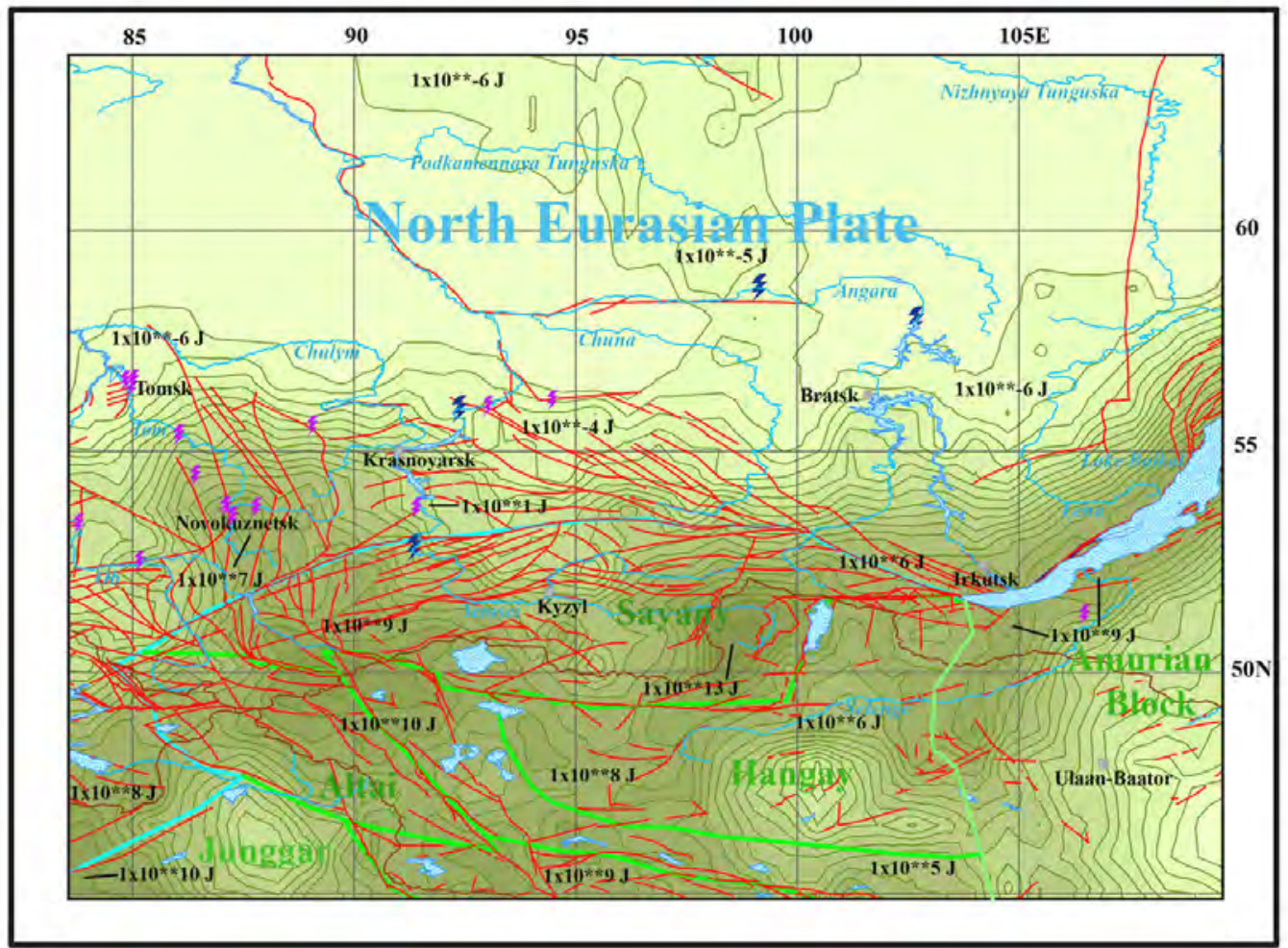

Figure 5. Main power-stations and the seismic energy distribution in south Siberia and adjacent territories. For captions see Figures 1 and 3.

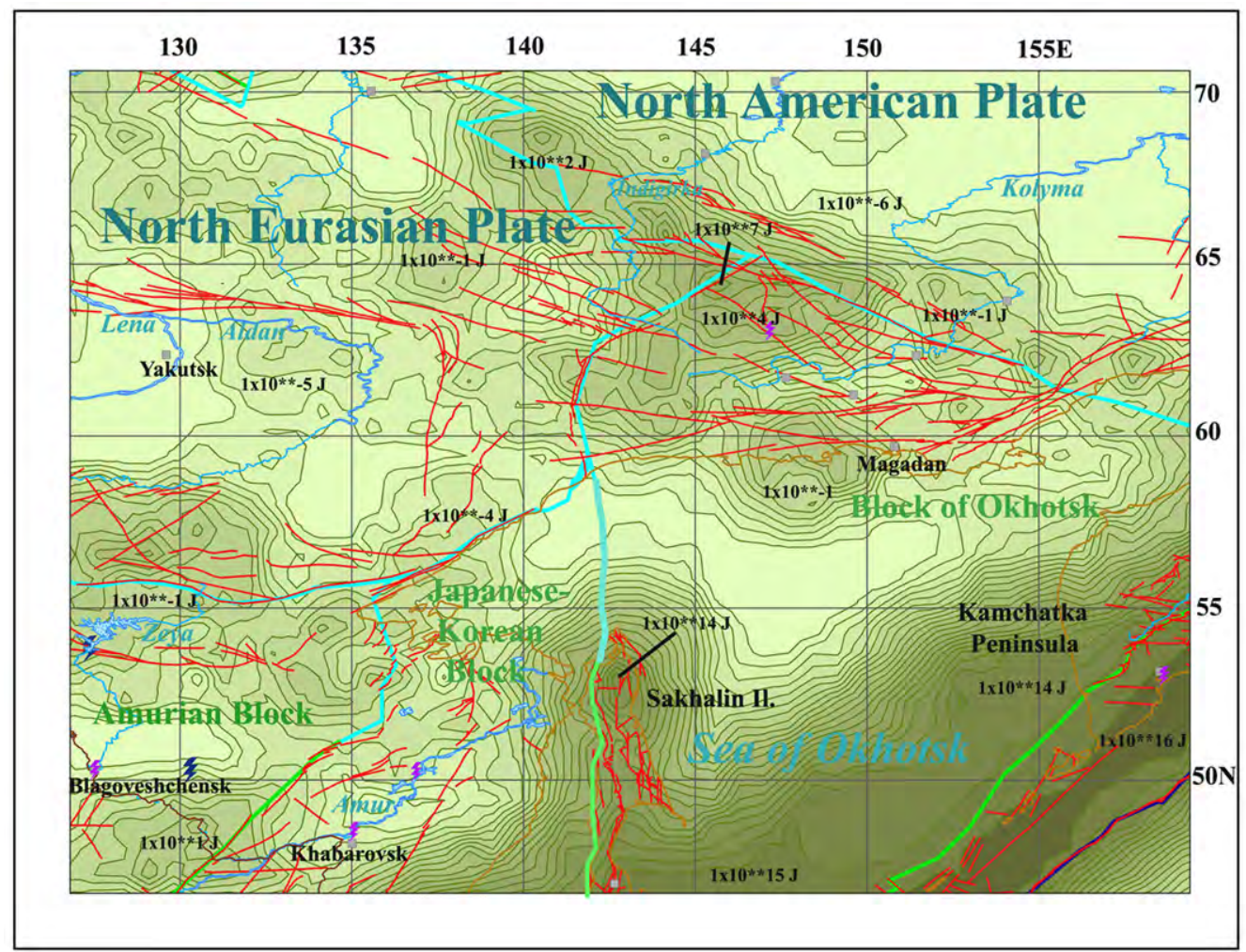

Figure 6. Main power-stations and the seismic energy distribution in the central part of the Russian Far East. For captions see Figures 1 and 3. 
of increased seismicity are connected with active faults on boundaries of main lithosphere plates and the Amurian Block as well as inside the Japanese-Korean Block and the Block of Okhotsk, which are situated above the subduction zone of the Pacific Plate. But only insignificant quantity of power-stations gets in these zones.

\section{Northeast Asia}

The northeast Asia region lies on the junction of the three large structures: the north American Plate, Block of Okhotsk and Bering Block of the north Pacific transit zone (Figure 7). Block boundaries go along zones of active faults, some of which are situated above subduction zone of the Aleutian and Kuril-Kamchatka arcs. The intensity of the seismic energy releasing increases on above mentioned boundaries up to $1 \times 10^{3} \mathrm{~J}-1 \times 10^{7} \mathrm{~J}$ in the Koryak Territory near the Bering Sea cost and $1 \times$ $10^{9} \mathrm{~J}-1 \times 10^{15} \mathrm{~J}$ in north Kamchatka, but the most north part of the region including the Bilibin Station area is practically aseismic. A small increasing up to $1 \times 10^{-6} \mathrm{~J}$ can be seen only near Pevek on the East Siberia Sea cost (see Figure 7).

Northwest, rarely near latitudinal active faults predominate in the north part of the region corresponding to left-lateral slips with compression components. They change on mainly right-lateral northeast slips. A photointerpretation of cosmic images fulfilled by Yu. Gatinsky shown the existents here lineament systems as coinciding with active faults as transverse to them. Latter can correspond to some older fault systems. Earthquake magnitudes inside the continent as a rule don't exceed 4.0 - 5.9 with hypocenters' depth 30 - 40 km and only in the Kamchatka Arc and adjacent part of the Sea of Okhotsk there are earthquakes with M 6.0 - 8.0 and more deep hypocenters (up to $640 \mathrm{~km}$ ). The compression predominates here in the trench and arc. The north American Plate moves on azimuth 157SE with the velocity $22.3 \mathrm{~mm} / \mathrm{y}$ according to measurements in the Bilibin GPS Station. The vertical upwarping reaches $2.6 \mathrm{~mm} / \mathrm{y}$. The increased heat flow can take place in the Bilibin NPS area because east of it in the Chuckchee Territory the heat flow was measured as $60-80 \mu \mathrm{W} / \mathrm{m}^{2}$ and the geothermal gradient as $25^{\circ}-30^{\circ} / 1000 \mathrm{~m}$ [8].

Therefore, we can note that the increased seismicity coincides in northeast Asia, as in previous regions, with boundaries of plates and blocks. It requires choosing selectively areas for projecting and construction new energetic objects in the region. The Bilibin NPS only operating here is situated in the aseismic area without any manifestations of modern tectonic activity but the increased heat flow can't be excluded within its area.

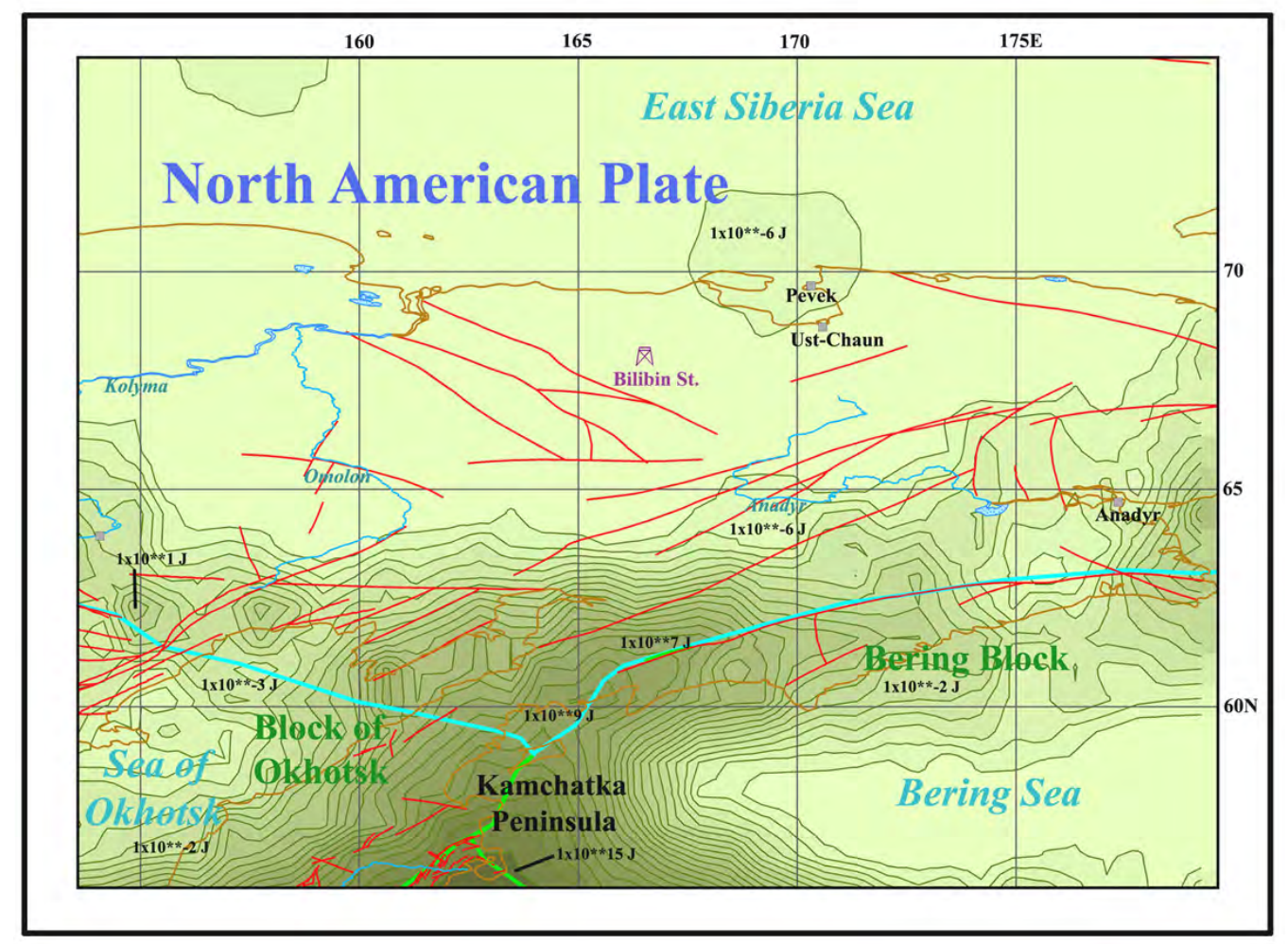

Figure 7. The Bilibin nuclear power-station and the seismic energy distribution in northeast Asia. For captions see Figures 1 and 3. 


\section{Conclusions}

The fulfilled seismic-geodynamic monitoring permits to make following inferences concerning the main energetic objects in the territory of east Europe and north Asia.

1) The majority of NPS as well as main HES and TES in this territory are situated within the north Eurasian and north American lithosphere plates with the weak level of seismicity or complete absence of it and active up-todate tectonic movements besides some exogenetic processes (karst, landslides and others).

2) Some operating, projected and closed NPS as well as large HES and TES are disposed near to zones of moderate seismicity $\left(1 \times 10^{-4} \mathrm{~J}-1 \times 10^{3} \mathrm{~J}\right)$ in Baltic, Byelorussia, south Ukraine, northwest Russia, the Urals and south Siberia.

3) Other stations in east Crimea, near north Caucasus, in Kazakhstan and within certain areas in south Siberia lie in zones of active faults and more increased seismicity up to $1 \times 10^{4} \mathrm{~J}-1 \times 10^{9} \mathrm{~J}$. Some of them are situated within blocks of the transit zones, which divide main lithosphere plates and are characterized by the increased tectonic mobility.

4) The electric stations in central Asia, north Caucasus and Transcaucasus including the Yerevan NPS undergo the largest seismic danger since they lie in zones of the maximal interaction of the Eurasian, Arabian and Indian plates, where collision processes have not stopped. The intensity of the releasing there seismic energy reaches 1 $\times 10^{10} \mathrm{~J}-1 \times 10^{14} \mathrm{~J}$.

5 ) It is reasonably during projecting new electric stations to avoid areas within interblock zones in the transit zones, in which as a rule the maximal seismic energy releases. Methods of such interblock zones establishing and the calculation energy in them are done in the work [9].

\section{Acknowledgements}

This investigation is fulfilled with assistance of the Presidium RAS, Moscow (Program 4 "Appraisal and means of decreasing consequences of up-to-date tectonic movements and earthquakes in regions of existing and pro- jected nuclear power-stations in the territory of Russia and neighboring foreign countries") and Russian Foundation for Basic Research (Project no. 09-05-00666).

\section{References}

[1] V. G. Trifonov, O. V. Soboleva, R. V. Trifonov and G. A. Vostrikov, "Recent Geodynamics of the Alpine-Himalayan Collision Belt,” GEOS, Moscow, 2002.

[2] D. V. Rundkvist, Yu. G. Gatinsky, W. A. Bush and V. G. Kossobokov, "The Area of Russia in the Present-Day Structure of Eurasia: Geodynamics and Seismicity,” In: D. K. Chowdhury, Ed., Computational Seismology and Geodynamics, American Geophysics Union, Washington, 2005, pp. 224-233.

[3] Yu. G. Gatinsky, D. V. Rundquist and Yu. S. Tyupkin, "Block Structures and Kinematics of Eastern and Central Asia from GPS Data,” Geotectonics, Vol. 39, No. 5, 2005, pp. 333-348.

[4] Yu. G. Gatinsky, D. V. Rundquist and Yu. S. Tyupkin, "Block Structure and Kinematics of Western Eurasia According to GPS Data,” Geotectonics, Vol. 41, No. 1, 2007, pp. 26-37. doi:10.1134/S0016852107010049

[5] Yu. G. Gatinsky, D. V. Rundquist, G. Vladova and T. Prokhorova, "Up-to-Date Geodynamics and Seismicity of Central Asia,” International Journal of Geosciences, Vol. 2, No. 1, 2011, pp. 1-12. doi:10.4236/ijg.2011.21001

[6] Yu. G. Gatinsky, V. I. Zakharov, G. L. Vladova, T. V. Prokhorova and Yu. N. Sirota, “Applying of the Remote Sensing for Choosing an Area of the Nuclear Power-Station Construction," Proceedings of IKI Conference Modern Problems of the Earth Remote Sensing from Cosmos, Moscow, 15-19 November 2010, pp. 262-263.

[7] K. G. Levi, S. I. Sherman and V. A. San’kov, "Modern Geodynamics of Asia,” In: K. G. Levi and S. I. Sherman, Eds., Actual Problems of Modern Geodynamics of Central Asia, In Russian, Siberian Branch of RAS, Novosibirsk, 2005, pp. 253-267.

[8] L.V. Podgornyi, "Heat Flow Map of Polar Territories in 1:30000000 Scale,” In Russian, Nedra, Moscow, 1997.

[9] Yu. G. Gatinsky, T. V. Prokhorova, D. V. Rundquist and G. L. Vladova, "Zones of Catastrophic Earthquakes of Central Asia: Geodynamics and Seismic Energy,” 2009. http://dx.doi.org/10.2205/2009ES000326 